\title{
ERRATUM
}

\section{Erratum to "Effects of photoregime on the diel rhythmicity of male responses to sex pheromones in Glyphodes perspectalis (Lepidoptera: Crambidae)"}

\author{
Kei Kawazu, ${ }^{1, *, \dagger}$ Suguru Nakamura, ${ }^{2}$ Hiroshi Honda ${ }^{3}$ and Tarô AdaTI ${ }^{2}$ \\ ${ }^{1}$ Interdisciplinary Graduate School of Science and Engineering, Tokyo Institute of Technology; Midori-ku, Yokohama 226-8502, \\ Japan \\ ${ }^{2}$ Faculty of International Agriculture and Food Studies, Tokyo University of Agriculture; Setagaya-ku, Tokyo 156-8502, Japan \\ ${ }^{3}$ Graduate School of Life and Environmental Sciences, University of Tsukuba; Tsukuba 305-8572, Japan
}

(Received 27 March 2009; Accepted 13 October 2009)

Ref.: Appl. Entomol. Zool. 45(1): 169-176 (2010)

The last author's name should have been "Tarô AdATI" instead of "Tarô AADTI". The correct author line appears above.

\footnotetext{
* To whom correspondence should be addressed at: E-mail: kkawazu@affrc.go.jp

$\dagger$ Present address: National Agricultural Research Center, Kannondai 3-1-1 Tsukuba, Ibaraki 305-8666, Japan. DOI: 10.1303/aez.2010.347
} 